\title{
The Realistic Difficulties and Countermeasures of Implementation of the "Little Village Official" Policy Zhen WANG ${ }^{1, a^{*}}$, Qiang $\mathrm{LI}^{2, \mathrm{~b}}$
}

${ }^{1}$ The School of Law and Politics, Tianjin university of technology, Tianjin, China

${ }^{2}$ The School of Law and Politics, Tianjin university of technology, Tianjin, China

awz928110771@163.com, rlylq@tjut.edu.com

Keywords: The little village official; Difficult employment; The talent needs; Policy implementation

\begin{abstract}
There are about 20 years after the implementation of little village official policy till 2015, Implementation of the "little village official" policy is not only relieve the college graduates' employment problem, but also meet the needs of the talents in the process of new rural construction. The process of Policy implementation is never smoothly because of serious problems. Through the study of implementation of little village official, we can provide some practical advice by means of statistical analysis technique.
\end{abstract}

\section{Introduction}

The "little village official" refers to the university graduates served as Party secretary, committee director assistant or other village "two committees" position of the village in the village (community) . After relevant government departments strict examination, including the written test, interview and physical examination, graduates can be the "little village official" .It can be said that" little village official" are excellent graduates students. From the beginning of 2005, the relevant departments have held the meeting of "little village officer" to arrange specific work. The "little village official" policy get into a comprehensive development period gradually.

\section{The Background of "Little Village Official" Policy}

The implementation of any policy has its specific policy background, implementation of the " little village official" policy has its own policy background.

The Severe Employment Situation of College Students. From the beginning of the 1999, college enrollment in our country increase fast because of the effect of the domestic economic development level and economic structure, limited employment opportunities can not meet the employment needs of the graduates. Figure 1.

Table 1 2005-2012 college graduates employment statistics

\begin{tabular}{|c|c|c|c|}
\hline year & $\begin{array}{c}\text { The number of } \\
\text { graduates(million) }\end{array}$ & $\begin{array}{c}\text { The number of the } \\
\text { unemployed(million) }\end{array}$ & $\begin{array}{c}\text { Rate of } \\
\text { employment }\end{array}$ \\
\hline 2005 & 3.4 & 0.79 & $76 \%$ \\
\hline 2006 & 4.13 & 0.91 & $77 \%$ \\
\hline 2007 & 4.95 & 1.45 & $70 \%$ \\
\hline 2008 & 5.59 & 1.73 & $68 \%$ \\
\hline 2009 & 6.11 & 1.96 & $68 \%$ \\
\hline 2010 & 6.30 & 1.76 & $72 \%$ \\
\hline 2011 & 6.60 & 1.47 & $77.8 \%$ \\
\hline 2012 & 6.80 & 1.76 & $71 \%$ \\
\hline
\end{tabular}

It can be seen from table 1: It shows the increasing tendency of the number of Chinese college graduates from 2005 to 2012.The number of unemployed college graduates is too large. The high unemployment rate leads to the waste of human resources and passive long-term unemployment will 
have great adverse psychological shadow on people. The current job market situation is grim: City employment market demand tends to saturation. The implementation of "little village official" policy is based on the basic situation that there has no big breakthrough in the city employment market. The little village official" policy alleviate the pressure on employment of college graduates to some extent.

The Need for High-Quality Talents In the Construction of Socialist New Countryside. Since 1978, city Economic and social have a rapid development. While the majority of the rural region' development is slow. The gap between urban and rural areas is widening. Because of this, rural elite talent migrate to urban area through a variety of ways. The lack of talent is unable to undertake the task of the socialist new countryside construction in rural areas. One of the main purposes of little village official policy is attracting high-quality talent to join the construction of new countryside and improve the management of countryside.

\section{The Realistic Plight of the "Little Village Official" Policy}

The implementation process of little village official" policy will encounter with sorts of problems. We should find out the deficiency of policy and fill the loopholes of the policy process.

The Conflict between the "Little Village Official" Policy and Law. According to eleventh stipulation of "The PRC Village Committee Organization Law": The village committee director, deputy director and members, elected directly by the villagers. No organization or individual can appoint or replace members of the villagers' committee. The "little village official" policy says: the selection of little village official from college graduates. The little village official usually served as Party secretary ,committee director assistant or other village "two committees" position of the village in the village (community). Obviously, the" little village official" is also a member of the village committee. On the basis of the "PRC Village Committee Organization Law" and other relevant villager autonomy, village committee member must be the villager of this countryside. and elected by local villager. Obviously, the "little village official" policy is not within the law.

Part of The "Little Village Official" Focus on Utilitarianism. The "little village official" policy has attracted a large number of graduates. The reason why graduates choose to be a village official is different, but majority of college graduates just for utilitarianism. The experience of village official make him more competitive than others when he is applying for civil servants or postgraduate degree in the future. The proportion of the graduates who focused on rural construction is only $20 \%$. Obviously, the "little village officer" policy can not been used for this graduates.

Professional Knowledge of the "Little Village Official" Can Not Meet the Actual Needs of Rural Development. At present, the development of the rural areas need high-tech knowledge. But after the selection of the "little village officer", the farmers found that professional knowledge of the little village official can not meet the actual needs of rural development. The data of student information and career center show that $45 \%$ of the "village official" has the philosophy, literature and education background of social science. The number of village official who is major in agriculture, husbandry, animal health and other related profession is very small. As the nationwide investigation of employment situation of college graduates show: the "little village official" majoring in agronomy accounted for only $4 \%$, medical profession accounted for $2 \%$, technology profession accounted for $6 \%$, law profession accounted for 3\%, economics and management professional accounted for $22 \%$, philosophy and history profession accounted for $18 \%$. Figure 2 . 


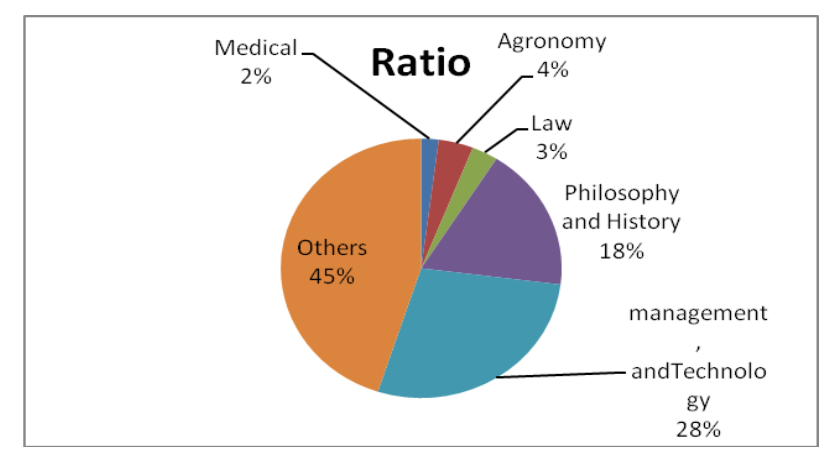

figure. 1 the professional distribution of the " little village official"

The Lack Of Effective Management of "Little Village Official". At present, the management system of "little village officer" is still not perfect. First of all, in some areas, "the little village official" have not go to the countryside to carry out the work, but go to the town government to help complete the relevant job. The absence of "little village official is bound to affect the efficiency of the "little village official" policy. Secondly, the relevant state laws and regulations lack clear provisions of the "little village officer". So the "performance appraisal of little village official" is difficult to really start. Moreover, the income of little village official is too low, the current monthly living allowance average more than 2000Yuan which may affect the enthusiasm of little village official. Finally, the unknown future will make the "little village" official hard focused on work. According to the relevant policies and regulations, "little village officer will signed a 3 year contract with the relevant departments. So, They have to consider how to live well after the expiration.

\section{The Countermeasures of "Little Village Official" Policy Implementation}

A series of problems appearing in the process of "little village official" policy implementation, this paper try to give the following countermeasures from public policy perspective.

Improve the Relevant Laws and Regulations of the "Little Village Official" Policy. The rational policy is a fundamental prerequisite for the effective implementation of the policy. The legal problem of "village official" policies has not been well resolved. Therefore, We should revise PRC Village Committee Organization Law" as soon as possible to ensure "voters status" of " little village official".

Improve Selection and Appointment Mechanism of "Little Village Officer". The effective implementation and rationality of the policy are closely related. The internal selection and appointment mechanism of "the little village official" policy is unreasonable. It hindered the effective of "little village official" policy. This article give some advices from the following two aspects: Firstly, the best service place of "little village official" is the origin. Because of the original account does not exist, the little "village official" policy become more legitimate. secondly, from the practical point of view, to carry out the work in a familiar environment, It will undoubtedly reduce the difficulty of the work; when it comes to the conflict between little village officer" profession and rural area actual development needs, the selection of "little village officer" should in lines with the development of the rural areas.

Improve the Management and Assessment of "Little Village Officer". To improve the management and assessment of the "little village official". Firstly, we need to define "the little village official" job responsibilities clearly ; secondly, we should establish a system of the supervision and assessment for the "little village official" . The specific work can be divided into the following several aspects: 1.Evaluation step by step. Due to the special character of rural work, the evaluation work can be divided into 3 aspects: early, middle and late stage. 2. Pay attention to the process, strengthen supervision. Not only should we strengthen the study of "little village official" 
achievements, but also strengthen the study of "village official" daily work. Therefore, we can find problems and correct them timely.3.Comprehensive evaluation. In order to ensure the fairness and justice of the assessment results, the annual comprehensive assessment work can be completed by the supervisor and the villagers together. Finally, Paying attention to the appraisal result. Various awards can be given to the outstanding "village official". Kinds of punishments can be given to the "village official who do not do well in the work.

Improve the "Little Village Officer" Pays, Welfare. If lack of policy resources, the implementation of the policy will inevitably lead to the failure of the policy. The necessary funding is the material basis of policy implementation. To improve the "little village officer" wages, welfare is not only beneficial to improve the work enthusiasm of "little village official, but also conducive to enhancing the stability of policy. So it is necessary to improve the "little village officer" salary. We can encourage the "little village officer" to increase their own income and increase the income of farmers through the form of entrepreneurship. Furthermore, we can provide the "little village officer" with some preferential policies to solve the any menace from the "rear".

Strengthen the Education and Cultivation of the "Little Village Official". The quality of policy implementer will affect the effect of the policy. If you want to ensure policy to achieve the desired effect, you need to strengthen the education and cultivation of "little village official". According to the obvious advantages of knowledge, strong learning ability, but lack of specific practical experience of "little village official, We will be able to put the selection work of "little village official" ahead to the year before graduation. The graduate who has been selected as "little village officer" will be classified as "village class". In the last year of University, "little village officer" relying on the favorable platform of University to strengthen the study of rural issues. In spare time, in order to deepen knowledge and understanding of rural areas," village class" students can be organized to rural areas. In the specific work process, "little village official" may encounter a variety of problems. The relevant units should provide guide and support with all kinds of doubts and demands of "little village official".

\section{Summary}

In order to make the "little village official" policy perform well, to achieve the desired effect of the policy, this paper argues that we should improve relevant laws and regulations to make the "little village official" policy legitimate. Secondly we should adjust and improve the selection and appointment and the daily management and evaluation mechanism of "little village officer" .Finally, we should improve the "little village officer" salary, and increase the "little village officer" educational investment.

\section{References}

[1]F.M. Ye: Theory, Vol. 43 (2014) No.8,P. 78-79. (In Chinese)

[2]J.C. Sun: Chinese Son and Daughter, Vol. 28 (2013) No. 4,P.23- 24. (In Chinese)

[3]Q.Y. Jiang: Modern Commerce and Industry, Vol. 33(2010) No.8,p. 31-32.

[4]The National Higher Education Information and Career Guidance Center: The employment situation of college graduates in China (2005 2012)(Beijing: Peking University press, China 2013). (In Chinese)

[5]S.D. Zhang, R.Q. King: Work of Talent Development, Vol. 56(2007) No.29,P. 25-27. (In Chinese)

[6] W. Hou: Law and Society, Vol. 65 (2010) No. 11,P.59-60. (In Chinese)

[7] Y. An: Agricultural Economy, Vol. 86(2012) No.26, P.55-56. (In Chinese)

[8]T. Yu: The research of the problem of College graduates' employment(MS., Jiangsu University, 
China2010), P.28. (In Chinese)

[9]G.L. Yang : ZheJiang Provincial Party School, Vol.72( 2013) No. 35. P.35-39. (In Chinese)

[10]Z.P. Wang: The Study On the Long Term Mechanism of Little Village Officials(Beijing: Economic Science Press,China2012,p115.). (In Chinese) 